\title{
Iatrogenic Cushing's syndrome induced by topical steroid therapy misuse
}

\section{Selma El Kadiri, Sara Elloudi, Rhizlane Chaoui, Hanane Bay Bay, Fatima Zahra Mernissi}

\author{
Department of Dermatology, CHU Hassan II, Fez, Morocco
}

Corresponding author: Selma El Kadiri, MD, E-mail: elkadiri-s@hotmail.com

Sir,

Topical corticosteroids are widely administrated in several diseases including inflammatory, allergic, and auto-immune dermatosis [1]. A prolonged application can lead to several adversary effects [2]. We report a case of an adult Cushing's syndrome due to over usage of topical steroid for psoriasis

A 50-year-old female diagnosed with interphalangeal distal articular and cutaneous psoriasis 15 years before treated with injection once-a-week of methotrexate and topical steroid therapy. The cutaneous relapses were characterized by several episodes per year. She was prescribed topical clobetasol propionate and injection once-a-week of methotrexate. She reported an almost daily application of corticosteroid therapy on a large surface with a few therapeutic windows of 7 days. She presented to our consultation complaining of asthenia.

Physical examination showed moon facies, facial plethora, central obesity, buffalo hump, pendulous abdomen, hirsutism (Fig. 1). They were also several and confluent erythematous papules and plaques interesting the trunk, limbs, and back (Fig. 2). Blood pressure was $180 / 110 \mathrm{mmHg}$, heart rate was $80 / \mathrm{min}$, Height $1.69 \mathrm{~m}$, weight $110 \mathrm{kgs}$, and body mass index $40 \mathrm{~kg} / \mathrm{m}^{2}$. On laboratory examination, fasting blood glucose: $140 \mathrm{mg} / \mathrm{dl}$, high-density-lipoprotein: $41 \mathrm{mg} / \mathrm{dl}$ $(\mathrm{N}: 45-55)$, total cholesterol: $240 \mathrm{mg} / \mathrm{dl}$ low-densitylipoprotein: $125 \mathrm{mg} / \mathrm{dl}$ (N: 0-130); serum cortisol $<0,3 \mu \mathrm{g} / \mathrm{dL}$ at $8.00 \mathrm{am}$, low adrenocorticotropic hormone (ACTH) levels 1.7pg/ml (N: 4.7-48.8pg/ml).

According to these findings, the patient was diagnosed with iatrogenic Cushing's syndrome induced by

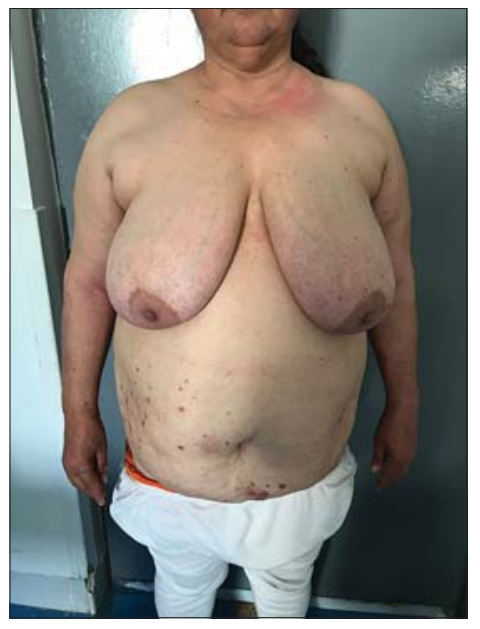

Figure 1: Moon facies, facial plethora, buffalo hump.

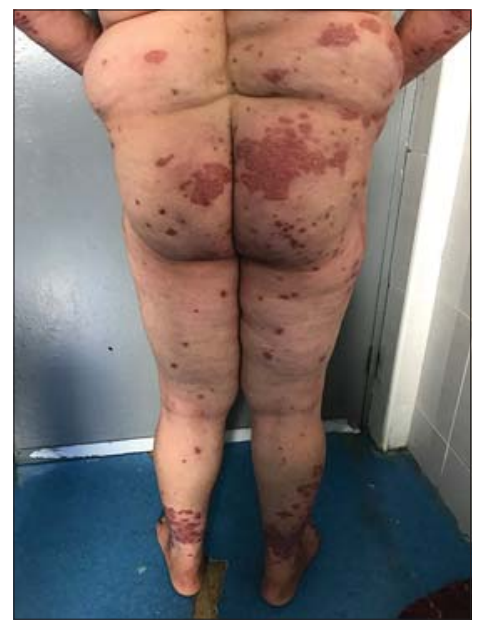

Figure 2: Several scaly and erythematous plaques and patchs on the back and lower limbs.

topical corticosteroids misuse. Clobetasol propionate cream was discontinued and the patient has initiated ustekinumab. She was also prescribed low prednisone 
doses to avoid the adrenal crisis and was followed by a dietitian.

Topical corticosteroids are commonly prescribed in dermatology. The occurrence of Cushing's syndrome secondary to topical steroid therapy is rare in adults [2] Most observations have been reported among the pediatric population. Proprionate clobetasol is class I ultra-high potency steroid therapy can induce local adverse reactions such as atrophy, purpura, striae, but also systemic effects such as hypertrichosis, deep vein thrombosis, and adrenocortical insufficiency [1]. The suppression of the hypothalamic-îtuitary-adrenal axis can occur after the weekly application of $50 \mathrm{mg}$ of clobetasol propionate [3]. Moreover, Van Velsen et al. described a reduction of cortisol levels in patients with atopic dermatitis even after a single whole-body application of clobetasol propionate cream [4]. The particularity is that our observation displays all the systemic features of Cushing's syndrome while clinical features in previous cases were limited.

To minimize these adversary drug reactions, as specialists we should witness our patients of their false perception of safety topical therapy compared to systemic treatments. On the other hand, we should inform and aware practitioners of potential adversary drug reactions considering that are underestimated.

\section{Consent}

The examination of the patient was conducted according to the principles of the Declaration of Helsinki.

The authors certify that they have obtained all appropriate patient consent forms, in which the patients gave their consent for images and other clinical information to be included in the journal. The patients understand that their names and initials will not be published and due effort will be made to conceal their identity, but that anonymity cannot be guaranteed.

\section{REFERENCES}

1. Negrini S, Murdaca G, Ferone D, Borro M. Adult iatrogenic Cushing's syndrome induced by topical skin corticosteroid misuse. Therapie. 2019;74:547-9.

2. Oray M, Abu Samra K, Ebrahimiadib N, Meese H, Foster CS. Long-term side effects of glucocorticoids. Expert Opin Drug Saf. 2016;15:457-65.

3. Drug Information Fulltext. American Society of Health-System Pharmacists. 2005; file 229-1.

4. van Velsen SG, De Roos MP, Haeck IM, Sparidans RW, BruijnzeelKoomen CA. The potency of clobetasol propionate: serum levels of clobetasol propionate and adrenal function during therapy with $0.05 \%$ clobetasol propionate in patients with severe atopic dermatitis. J Dermatolog Treat. 2012;23:16-20.

Copyright by Selma El Kadiri, et al. This is an open access article distributed under the terms of the Creative Commons Attribution License, which permits unrestricted use, distribution, and reproduction in any medium, provided the original author and source are credited.

Source of Support: Nil, Conflict of Interest: None declared. 